\title{
Editorial
}

Hamilton Lima Wagner

Diretor de Publicações

\section{O perfil dos autores e dos trabalhos publicados pela RBMFC}

Após a seleção dos trabalhos para a publicação de quatro exemplares da RBMFC, após o seu processo de revitalização, vai se delineando um perfil de trabalhos e autores que publicam em nossa revista. Incluímos nesta análise a revista de número 6 , que já está com sua seleção de artigos concluída e será distribuída em breve, considerando o esforço em regularizar os prazos da publicação. Foi considerado neste levantamento o autor principal. Foram analisados ao todo 22 trabalhos, sendo 20 artigos originais e 2 relatos de caso. São 10 artigos e um relato de caso de preceptores de residência em MFC; 6 artigos de autores de outras profissões de saúde, a maioria ligadas ao meio acadêmico: enfermagem (2) , psicologia e micro biologia e saúde coletiva (2); 3 artigos de autores que atuam na graduação de medicina, nas áreas de APS/MFC; 1 artigo e 1 relato de caso de autores que atuam como MFC. Segundo as regiões do país, temos 9 autores do sudeste, 8 autores do sul, 4 do nordeste e 1 do norte do Brasil. Quanto à temática os artigos estão assim distribuídos: diagnóstico e terapêutica (10), comunidade (4), epidemiologia (2), qualidade (2); sistemas de informação (1); registros médicos (1), política de atenção primária (1).

Este perfil, mesmo que em um momento inicial já nos permite vislumbrar pontos positivos de nossa publicação, todos relacionados à diversidade. A contribuição de autores a atuar em vários campos da MFC e da APS e com representatividade em todo o território nacional é um fator de extrema relevância para o veículo científico oficial da SBMFC, ainda mais quando se considera a proposta de uma sociedade de âmbito nacional. Outro aspecto é o da participação de autores de outras áreas disciplinares que enriquecem a produção de conhecimento e a troca de informações no campo da MFC e da APS. A presença preponderante de autores com vínculos de formação médica graduada é pósgraduada é um fato muito positivo e estimulante. E por fim vale destacar o número de artigos que abordam temas variados e tratam das várias dimensões do campo da MFC 
e da APS, tal como está definido nas nossas normas de publicação. Esta diversidade, entendida em todos os aspectos acima citados, garantem ao leitor da revista e à difusão científica em MFC a riqueza que deve ser buscada em veículos científicos, proporcionando o avanço do conhecimento e da área de atuação da especialidade, a qualificação e o processo de educação continuada dos profissionais da área.

Ainda não alcançamos certamente todos os objetivos. A destacar citamos a necessidade da recepção de um maior volume de artigos, especialmente dos MFC e o incentivo a um maior diálogo e intercâmbio à nível internacional com a publicação de autores que atuam, como profissionais e pesquisadores em outros países. Para fomentar este conhecimento de autores estrangeiros, estamos estabelecendo um acordo para a distribuição, pelo preço de custo, da American Family Physician em nosso país. Esperamos que esta iniciativa obtenha uma grande adesão de nossos associados, o que certamente irá trazer novas perspectivas para a inserção da SBMFC na produção do conhecimento. Também pretendemos para breve a publicação das primeiras Diretrizes em MFC, que estão sendo elaboradas por um grupo técnico com a coordenação da SBMFC. A criação desta sessão irá contribuir em muito para o processo de educação continuada de nossos associados. 